\title{
Inmigrantes latinoamericanos en ciudades globales: aproximaciones interdisciplinarias en el análisis de las prácticas comunicativas, mediáticas y culturales
}

\author{
Jessica Retis \\ California State University Northridge, Estados Unidos \\ jessica.retis@gmail.com
}

Recibido: 19/7/2018 / Aceptado: 28/9/2018

doi: 10.26439/contratexto2018.n030.3147

\begin{abstract}
Resumen. El estudio de las prácticas comunicativas, mediáticas y culturales en contextos diaspóricos plantea una serie de desafíos teóricos y metodológicos. En esta contribución, examinamos estos retos y argumentamos de qué manera las aproximaciones interdisciplinarias constituyen un ensamblaje enriquecedor que nos permite analizar y comprender los procesos de llegada y asentamiento de los inmigrantes latinoamericanos en ciudades globales. El estudio comparado de las diásporas latinoamericanas y los medios en entornos urbanos nos permite, además, identificar las tendencias actuales. Partimos de los aportes que nos proporcionan los estudios sobre migraciones y los estudios de medios, para identificar el análisis crítico de la condición transnacional de los latinoamericanos que residen en ciudades fuera de la región. Analizamos cómo las evidencias de la génesis y la consolidación de las audiencias transnacionales y translocales han sido reconocidas tanto por el mercado publicitario como por las industrias privadas, y cómo, a pesar de esto, su estudio sigue siendo una cuenta pendiente por parte de las administraciones públicas en los países de origen y de destino.

Palabras clave: inmigrantes latinoamericanos / ciudades globales / consumo cultural / medios étnicos / diásporas y medios
\end{abstract}




\title{
Latin American immigrants in global cities: Interdisciplinary approaches to the analysis of communication, media and cultural practices
}

\begin{abstract}
Aвstract. The study of communication, media and cultural practices in diasporic contexts gives rise to a series of theoretical and methodological challenges. The current article examines these challenges and argues how interdisciplinary approaches constitute an enriching assembly which enables us to analyze and understand the process of arrival and settlement of Latin American immigrants in global cities. The compared study of Latin American diasporas and the media in urban environments also enables the identification of present trends. Migration and media studies function as a starting point towards identifying the critical analysis of the transnational condition among Latin Americans who reside in cities outside their region. We analyze how the genesis and consolidation of transnational and translocal audiences have been recognized by both the advertising market and private industries. Despite this, public administrations from countries of origin and destination still neglect their study.

Keywords: Latin American immigrants / global cities / cultural consumption / ethnical media / diasporas and media
\end{abstract}




\section{Introducción}

$\mathrm{A}$ lrededor de 30 millones de latinoamericanos y caribeños viven en países distintos a los de su nacimiento (Martínez, Cano y Contrucci, 2014). Fuera de Latinoamérica, la mayor parte de ellos residen en Norteamérica (con Estados Unidos a la cabeza), Europa (principalmente en España), en menor proporción en Asia (con Japón como principal destino) y Oceanía (mayormente en Australia). En las últimas décadas, los migrantes latinoamericanos se han sumado además a un movimiento poblacional más amplio, que es el del incremento de residentes en las ciudades, a expensas del descenso de habitantes en áreas rurales. Hoy en día, más de la mitad de la población vive en zonas urbanas (54\%) y se espera que se incremente a $60 \%$ para el 2030 (United Nations, 2016). Si, por un lado, los distintos aspectos de las dimensiones económicas, sociales, políticas y culturales asociadas a los movimientos migratorios ponen de relieve la multiplicidad de significados de este fenómeno (Martínez, 2006); por otro lado, el creciente predominio de la migración entre ciudades latinoamericanas viene llamando la atención de los investigadores que reclaman mayores estudios empíricos en la región (Rodríguez, 2017).

En este artículo, abordamos una reflexión basada en investigaciones que hemos llevado a cabo a lo largo de la última década. Estos trabajos han intentado analizar y comprender las prácticas comunicativas, mediáticas y culturales de los latinoamericanos en las grandes metrópolis europeas, norteamericanas y asiáticas: desde la publicación del primer mapeo de medios dirigidos a inmigrantes en Madrid (Retis, 2006b), pasando por el estudio comparado de los consumos culturales y mediáticos de los inmigrantes latinoamericanos en entornos urbanos y rurales en España (Retis, 2011), el examen de las industrias culturales hispanas en Estados Unidos (Retis y Badillo, 2015), los circuitos culturales latinos en metrópolis estadounidenses con alta concentración de hispanohablantes (Retis y Badillo, 2018) hasta un estudio en curso de los medios dirigidos a inmigrantes latinoamericanos en Tokio. Nos hemos interesado por examinar el rol de los medios en los procesos de estratificación social en contextos transnacionales (Retis y Moreno, 2014), con particular énfasis en los entornos urbanos (Retis, 2014b; García, Retis y Román, 2016). Estimamos que la comprensión del origen y la consolidación de las diásporas latinoamericanas y sus medios en las ciudades del norte económico puede brindar pistas sobre la importancia de conformar aproximaciones interdisciplinarias cuando se diseñan estudios sobre las dimensiones económicas, sociales, políticas y culturales del transnacionalismo diaspórico.

Este ensayo aborda, en primer lugar, una revisión de los aportes interdisciplinarios en estudio de las migraciones y los medios de comunicación. En segundo lugar, se enfatiza la importancia de entender el contexto transnacional de los 
movimientos migratorios y la conformación de las diásporas latinoamericanas en el exterior, antes de abordar los estudios de medios. En tercer lugar, se subraya la importancia de entender la consolidación de las diásporas latinoamericanas en los entornos urbanos de las ciudades globales del norte económico para entender cómo los medios de comunicación dirigidos a inmigrantes construyen espacios de información, comunicación y autorrepresentación, sin olvidar que también fungen como espacios de comercialización para consumidores de productos y servicios específicos. Las reflexiones finales abogan por desarrollar estudios comparados de las múltiples dimensiones en los procesos de producción, distribución y consumo, que permitirán aportar más elementos para comprender las prácticas mediáticas en el transnacionalismo diaspórico de los latinoamericanos.

\section{Los aportes interdisciplinarios en los estudios sobre migraciones y medios}

Analizar y comprender el rol que cumplen los medios en el vivir transnacional y translocal de las diásporas contemporáneas requiere hilvanar un armazón teórico que incorpore el estudio de dos fenómenos que se han venido influenciando a lo largo de estas últimas cuatro décadas: por un lado, el impacto de la creciente desigualdad y las asimetrías que genera la economía global en el incremento de mano de obra laboral extranjera en las grandes "ciudades globales" (Sassen, 2003); en el caso de
Latinoamérica, el efecto de los reajustes neoliberales y el consecuente incremento de las migraciones internacionales hacia fuera de la región, principalmente a ciudades norteamericanas y europeas (Pellegrino, 2004; Martínez, 2011; Martínez, 2008; Retis, 2006a). Por otro lado, la evolución de los avances tecnológicos que propiciaron el abaratamiento de los costes de transporte y la accesibilidad a las nuevas tecnologías de información y comunicación, principalmente en los entornos urbanos de las grandes metrópolis (Castells, 2006; Sassen, 2001; Retis, 2011).

Incorporar las aproximaciones teóricas y metodológicas de los estudios sobre migraciones internacionales nos permite comprender, en primer lugar, que la relación entre migración y globalización ha formado parte del proceso de modernización y ha desempeñado un papel central en la expansión y desarrollo del capitalismo (Castells y Miller, 2004; Martínez, 2008; Sassen, 2003). En segundo lugar, que el proyecto liberal en materia de circulación de capitales y mercancías, sostenido por gran parte de los Estados centrales, entra en contradicción con los severos controles impuestos a la libre movilidad de trabajadores y la radicación de personas en los territorios nacionales de dichos Estados (Pellegrino, 2003; Naciones Unidas, 2004). En tercer lugar, que se han producido nuevas dimensiones en el debate sobre las relaciones entre ciudadanía y territorio, y entre ciudadanía e identidad nacional; pero también entre los "ciudadanos" y los que no lo son, es 
decir, entre los residentes extranjeros admitidos oficialmente y los que se encuentran en condición de "irregularidad" (Pellegrino, 2003; Naciones Unidas, 2004). En cuarto lugar, que las brechas de ingreso y los ciclos macroeconómicos desempeñan un papel central que se refleja en la magnitud y dirección de las corrientes migratorias (Solimano y Watts, 2005), pero también que las crecientes desigualdades y asimetrías de la economía mundial conducen a la provisión constante de mano de obra que trabaja de manera precaria (Sassen, 2003; Martínez, 2008).

Dentro del amplio abanico de aproximaciones teóricas para estudiar las migraciones surgió en los años noventa el transnacionalismo, que produjo un avance en los estudios críticos al promover la ruptura con el nacionalismo metodológico y la integración de las condiciones de origen y destino en los análisis (Guarnizo y Smith, 1998). Se comprende ahora que los migrantes no rompen con el país de origen, sino que reconfiguran un campo social transnacional, a través del cual la comunidad de origen se transforma en los lugares de destino (Canales, 2011). El pespunte del armazón lo proporcionan, por un lado, el análisis crítico desde las perspectivas poscoloniales que ayudan a comprender por qué y cómo los flujos de población siguen a los flujos de capital, pero en sentido inverso (Said, 1993; Mignolo, 2005; Quijano, 2007), mientras que, por otro lado, la perspectiva de las redes y cadenas migratorias permite comprender la reconfiguración de estos lazos en el transnacionalismo
(Levitt y Glick Schiller, 2004; Smith y Guarnizo, 1998).

Ahora podemos entender mejor la complejidad del vivir transnacional, tomando en cuenta las estrategias establecidas por los migrantes. En el caso de los latinoamericanos, podemos acercarnos a la condición diaspórica que se ha venido conformando en entornos translocales y que hace que se hayan producido relaciones transnacionales entre residentes en Sao Paulo y Tokio, Nueva York y Quito, o Madrid y Bogotá. La naturaleza del transnacionalismo diaspórico demanda, pues, analizar y comprender los espacios construidos por los migrantes más allá de las fronteras geográficas, para ahondar el análisis en los estudios de pertenencia, ciudadanía y convivencia intercultural.

Incorporar los aportes de los estudios culturales, la economía política, la sociología de los medios o la antropología cultural nos ayuda a comprender las tendencias de las prácticas culturales y mediáticas de las diásporas contemporáneas (Cottle, 2000; Husband, 2000; Sinclair y Cunningham, 2000). Se trata de examinar las complejas relaciones intra- e interétnicas en los grupos que se desplazan de manera temporal, permanente o a veces circular a otras áreas geográficas distintas de las de sus lugares de origen (Georgiou, 2006; Guillespie, 2003; Sreberny, 2003; Retis, $2006 b, 2011)$. En este contexto, el transnacionalismo diaspórico se advierte menos como un lugar y más como un espacio. Estas complejidades invitan a considerar la emergencia de formas contradictorias 
pero viables de "comunidades transnacionales imaginadas", especialmente a través de la participación selectiva y parcial en las prácticas comunicativas (Georgiou, 2006). Es preciso también tomar en cuenta las formas disímiles que se producen en diversos entornos, pues las prácticas culturales se conciben en el telón de fondo de la dispersión geográfica y la diversidad interna y cultural (Sreberny, 2003). En los últimos años, además, la mirada analítica ha transitado a observar ya no exclusivamente a los medios masivos tradicionales (legacy media), sino a sopesar el rol de los nuevos medios (new media) y los medios sociales (social media) en los estudios sobre diásporas contemporáneas (Matsaganis, Katz y Ball-Rokeach, 2010; Dwyer, 2010; Retis, 2011, 2014a).

Los estudios sobre las prácticas comunicativas y de consumo cultural resultan centrales en este contexto porque permiten comprender el rol de los espacios mediáticos en las migraciones (Retis, 2011), ya que los actuales procesos de globalización económica demandan replantearse la tradicional forma de observar las sociedades nacionales al convertirlas en sistemas de redes (Castells, 2006) que han dado lugar a la desterritorialización de la vida social, transformando sus dimensiones culturales (Appadurai, 1996) y reconfigurando nodos, particularmente evidentes en los entornos urbanos de las ciudades globales. Los estudios sobre las actuales prácticas comunicativas diaspóricas evidencian el anacronismo de las corrientes tradicionales y nos demandan aproximaciones interdisciplinarias que nos permitan entenderlas en el marco de los estados posnacionales y las formaciones supranacionales contemporáneas. $\mathrm{Al}$ estudiar los lazos establecidos entre, para y por las redes migratorias (Massey et al., 1994) podemos bosquejar los circuitos sobre los que circulan los espacios mediáticos de las migraciones contemporáneas (Retis, 2006b; Georgiou, 2006).

Comprender las complejidades macroestructurales de la producción, la circulación y el consumo mediáticos en entornos diaspóricos requiere echar mano de diversas corrientes de investigación, desde el estudio de los flujos y contraflujos de medios (Thussu, 2007), la conformación de las regiones lingüísticas de medios (Sinclair y Straubhaar, 2013), el estudio crítico de la formación y desarrollo de las industrias culturales (Yúdice, 2009; Dávila, 2001), hasta el examen de la transición de los medios de masas (mass media) a los medios de clases (class media) (Wilson, Gutiérrez y Chao, 2003). Los estudios desde el transnacionalismo diaspórico y los espacios mediáticos en entornos urbanos (Georgiou, 2006; Georgiou y Silverstone, 2007; Karim, 2003) son valiosas aproximaciones teóricas que nos ayudan a entender tanto las especificidades como las contradicciones de las prácticas comunicativas de los inmigrantes latinoamericanos en las grandes metrópolis (Retis, 2006b, 2011). En términos de García Canclini, nos encontramos ante sinergias de integración junto con segmentación, ya que las industrias culturales unifican y crean homogeneidad, pero también 
trabajan con diferencias étnicas, nacionales y de gustos, y engendran nuevas distinciones. No es un tema nuevo el de las coexistencias y tensiones entre lo que nos unifica y nos segmenta. Sin embargo, en sociedades que interactúan con la intensidad que hoy facilitan los viajes y las comunicaciones electrónicas, esta multidiversidad, más compleja, exige hablar de otro modo sobre lo que puede agruparnos. Una de las últimas formas de hacerlo es la de los estudios sobre consumo en el contexto de la globalización (2002, p. 25).

\section{La conformación de las diásporas contemporáneas}

Si bien la migración internacional no es un fenómeno nuevo en América Latina, fue en los años ochenta cuando se empezaron a generar importantes cambios en la región: las migraciones no solo se intensificaron, sino que también se extendieron (Canales, 2006). Por otro lado, tal como lo hemos venido comprobando en el trabajo de campo, no se trata de analizar procesos estáticos, sino que nos encontramos con una multiplicidad de movimientos de concentración y dispersión geográfica que varían a lo largo del tiempo y las condiciones geopolíticas, socioeconómicas y culturales. En Estados Unidos, por ejemplo, los latinos empezaron por concentrase en la zona suroeste, la zona norte y sur de la costa este y la zona de los lagos. Sin embargo, en años recientes, se han intensificado los procesos de dispersión geográfica hacia zonas que por vez primera ven crecer la presencia latina, como Dakota del Norte, Alabama, Georgia, Pensilvania, Luisiana o Utah, por ejemplo (Stepler y Lopez, 2016). Del otro lado del Atlántico, si bien al cambio de siglo la mayor concentración de latinoamericanos se ubicó en los países del sur del continente, a raíz de los años de recesión económica se han venido produciendo nuevos patrones de dispersión geográfica que apuntan a Europa del norte (Retis, 2011). En la zona del Asia-Pacífico, la movilidad de sudamericanos hacia Japón ha protagonizado diversos momentos de crecimiento de migrantes $\mathrm{y}$, tal como se ha documentado, los recientes cambios en el panorama económico y político de ambas regiones apunta a un nuevo repunte de movilidad transnacional en el área del transpacífico (Retis, 2018b).

Examinar la evolución reciente de los flujos migratorios desde Latinoamérica hacia Europa, Norteamérica y Asia ha permitido estudiar el rol de sus "espacios mediáticos" (Retis, 2006b). Aunque los contextos históricos y geopolíticos son disímiles, el análisis de lo que ha venido aconteciendo a lo largo de las recientes décadas permite comprender los procesos de producción, circulación y consumo de medios hispanos en su carácter transnacional y translocal (Retis, 2006b, 2011). Aunque con diferencias en cuanto a la magnitud y las áreas geográficas de procedencia, a partir de los años ochenta se produjo un incremento significativo del desplazamiento de migrantes latinoamericanos hacia fuera de la región. En casi cuatro 
décadas, estos grupos han protagonizado una serie de sinergias económicas, sociales, políticas y culturales que afectan no solo a los latinoamericanos residentes en el Norte económico, sino a sus familiares en los lugares de origen. El análisis comparado de los procesos recientes nos permite identificar una tendencia generalizada hacia la homogeneización de los grupos latinoamericanos, impulsada principalmente desde el discurso económico-político y orquestada por el discurso de los medios de referencia. Se trata de lo que en otros trabajos se ha identificado como la tendencia a "la homogeneización de las heterogeneidades latinoamericanas" (Retis, 2018b).

En Estados Unidos, el censo ha ido evidenciando la acrecentada presencia de latinoamericanos. El uso, por parte de la administración pública, del término Hispanic a partir de los setentas no solo le imprimió un carácter pretendidamente homogéneo a comunidades heterogéneas y cambiantes, sino que fue retomado por las industrias culturales que reaccionaron a los cambios demográficos con campañas de marketing étnico (Dávila, 2001; Yúdice, 2009), lo que propició la creación desde arriba (top down) de una comunidad de consumidores pretendidamente homogénea y asequible como público objetivo (Retis, 2011). En contraste, los sondeos han apuntado cómo la mayoría tiende a identificarse más con sus países de origen (51 \%) - solo una cuarta parte prefiere el término Latino o Hispanic (Taylor, Lopez, Martínez y Velasco, 2012)-.
Mientras que los años ochenta en Latinoamérica fueron bautizados por los estudios críticos como la "década perdida" por los efectos de los reajustes estructurales y la crisis económica (Retis, 2006a), en Estados Unidos se afianzó the Hispanic decade (Yúdice, 2009; Dávila, 2001). Más de cuatro millones de personas llegaron desde Latinoamérica, el doble que la década anterior y el cuádruple que en los años sesenta (Pellegrino, 2003; Canales, 2006, 2011; Ennis, Ríos-Vargas y Albert, 2011). Hasta entonces el crecimiento demográfico se sustentaba en la población angloamericana, pero en los noventa, por primera vez, el avance demográfico provino de quienes eran considerados como la segunda minoría del país: $34 \%$ del crecimiento total de la población estadounidense fue de origen latino (Canales, 2011). Un nuevo repunte anotado por el censo del 2010 propició que se hablara de un nuevo Hispanic boom apuntado por los 50,5 millones censados que supusieron un $16,3 \%$ de la población estadounidense (Passel, Cohn y López, 2011). Y como en los tres censos anteriores, una vez más las industrias de medios reaccionó a los datos con diversas estrategias de producción y distribución de productos y servicios (Retis, 2013a). Mientras las proyecciones demográficas tuvieron impacto en el discurso público dominante que comenzó a reportar sobre el crecimiento de las comunidades latinas, en contrapartida, los estudios académicos críticos dieron cuenta de los obstáculos para el acceso a la educación, la sanidad, los servicios públicos y 
las cuotas de poder (Canales, 2006, 2011; Hondagneu-Sotelo, 2001; González, 2011). Para la mayor parte de los inmigrantes con raíces en Latinoamérica el ascenso social se complejiza. Por lo tanto, nos encontramos con la paradoja de que, aunque los hispanos crecen en sus condiciones de consumidores -tengan o no permiso para residir y trabajar-, no lo hacen de la misma manera en su condición de ciudadanía política y cultural. En otras palabras, la fuerza más evidente de la presencia hispana radica más en su condición de consumidores que en la de ciudadanos.

Al otro lado del Atlántico, los noventa fueron bautizados como la "década dorada" de las inversiones españolas en América Latina (Casilda, 2002), mientras que los procesos de emigración se incrementaron en lo que se bautizó como la segunda "década perdida" de la región. En España, los inmigrantes latinoamericanos fueron bautizados como "los preferidos del siglo xxI" porque se consideró que irrumpieron, en el contexto de la inmigración extracomunitaria en condiciones preferenciales, tanto en las administraciones públicas como en el sector empresarial y el clima de opinión (Izquierdo, López y Martínez, 2002). En contrapartida, los estudios académicos críticos sobre los procesos de inserción sociolaboral apuntaron por entonces las condiciones de vulnerabilidad en las que se insertaban (Pedone, 2006; Grupo Intesdisciplinario de Investigador@s Migrantes, 2010; Colectivo Ioé, 2008). De manera semejante a lo ocurrido en Estados Unidos, también en España diversas empresas de marketing étnico empezaron a elaborar campañas dirigidas a públicos latinoamericanos, creando entidades específicas para atender al número creciente de consumidores (Retis, 2006b). Esta tendencia continuó hasta bien entrada la crisis económica del sur de Europa, cuando los inmigrantes latinoamericanos comenzaron su dispersión geográfica hacia el norte europeo (Retis, 2011).

Del otro lado del Pacífico, las crisis económicas de los países de América Latina generaron flujos de emigración también hacia Asia. Por su parte, el auge de la economía japonesa, el envejecimiento de su sociedad y el aumento de la necesidad de mano de obra extranjera propiciaron la respuesta del Gobierno por la que se modificó el control de la inmigración y el reconocimiento de los refugiados en 1989; así, Japón comenzó a recibir la afluencia de trabajadores extranjeros. La reforma de 1990 permitió que los nikkeijin (descendientes de japoneses) pudieran obtener visas renovables para emigrar a Japón con base en la ascendencia japonesa de sangre u origen étnico. Mientras que los inmigrantes japoneses en América Latina son relativamente heterogéneos en cuanto a sus condiciones sociales y económicas, los inmigrantes latinoamericanos en Japón se han venido incorporando en sectores altamente homogéneos, independientemente de sus antecedentes y procedencia (Higuchi, 2006). Los descendientes de inmigrantes japoneses, que vuelven a Japón un siglo después de que sus antepasados iniciaron la migración internacional hacia América Latina han encontrado dificultades para 
la inserción sociocultural (Asakura y Murata, 2006). Algunos estudios han criticado cómo, a pesar de tener fenotipos japoneses, la mayoría de los nikkeijins latinoamericanos están expuestos a situaciones de discriminación no solo porque hablen portugués o español, sino por sus diferentes vestimentas o comportamientos (Tsuda, 2004).

\section{Construcción mediática de las migraciones contemporáneas}

Al comienzo de esta década, la Organización Internacional para las Migraciones examinaba la función que cumplen los medios de referencia tanto en la configuración de las opiniones como en las políticas públicas. El informe señalaba cómo, a pesar de la revolución en el ámbito de las comunicaciones, son muchos los que aún tienen información deficiente sobre la magnitud, el alcance y el contexto socioeconómico de la migración. Mantener el statu quo conlleva un triple riesgo: 1) la continuación de debates politizados solo servirá para promover agendas sectarias en lugar de favorecer intereses nacionales, regionales e internacionales más amplios; 2) dado que suele haber una fina línea divisoria entre el debate realista y honesto sobre los retos derivados de la migración y la adopción de imágenes estereotipadas que utilizan a los migrantes como chivos expiatorios, los intentos de promover un debate equilibrado corren el riesgo de pasar a ser principalmente reactivos ante los debates negativos actuales, en lugar de ejercer una función dinámica en lo que respecta a configurar esos debates, y 3) los esfuerzos orientados a la integración y la reintegración se verán inevitablemente debilitados a menos que los propios migrantes se conviertan en participantes activos del debate sobre la migración, en lugar de ser el tema del discusión (Organización Internacional para las Migraciones [OIM], 2011).

El reporte analizó los sondeos de opinión en ocho países receptores de inmigración internacional (Alemania, Canadá, España, Estados Unidos, Francia, Italia, Países Bajos y Reino Unido) y comprobó cómo los ciudadanos tienden a sobreestimar la dimensión real de la población inmigrante en sus países. Resumen cuatro tendencias en la cobertura de la migración: 1) hay una tendencia a proveer una cobertura episódica, como los incrementos repentinos debido a algún acontecimiento, generalmente de carácter negativo; 2) la "ilegalidad" como centro de atención; 3) la exageración de los hechos, y 4) la falta de contexto -en Estados Unidos, por ejemplo, rara vez la cobertura tiene en cuenta la función central del mercado laboral estadounidense en la determinación del volumen y las características de las corrientes de inmigrantes (OIM, 2011)-.

En su informe más reciente, OIM (2018) señala que los medios de referencia tienden a reflejar el lenguaje y los tópicos que los Gobiernos y los grupos en el poder prefieren, principalmente porque los reporteros usualmente dependen de los oficiales del gobierno para las fuentes de información, particularmente en asuntos políticos. Aunque se pudiera 
intuir que el surgimiento de la internet y las redes sociales está cambiando el panorama mediático, aún convivimos con la influencia de los grandes medios. En Estados Unidos, por ejemplo, casi la mitad de los ciudadanos (46\%) obtienen las noticias de las redes sociales; sin embargo, los medios de referencia, al menos por ahora, continúan marcando la agenda, o al menos se retroalimentan con las redes sociales. Según este informe, los medios continúan asociando la inmigración con las malas noticias y los contenidos negativos superan a los positivos en proporciones exageradas, con una elevada tendencia a relacionarla con asuntos de "ley y orden" o de "seguridad nacional". Se tiende a poner énfasis en el coste y el impacto fiscal, así como en una relación constante con el crimen. Además, se suele cubrir periodísticamente su presencia dividiéndolos de la población nativa, de tal manera que se les posiciona como amenazas a la identidad nacional, la cultura o a la cohesión social o se tiende utilizar metáforas retóricas para deshumanizar a los grupos migrantes y relacionarlos con desastres naturales o con figuras invasivas.

A lo largo de estos años, se ha analizado la cobertura periodística de los inmigrantes latinoamericanos en la prensa de referencia europea y norteamericana. Se ha examinado cómo los inmigrantes latinoamericanos tienden a no aparecer representados en condiciones normalizadas o con una perspectiva global, pues existe un escaso conocimiento de las condiciones geopolíticas y la magnitud de las migraciones
(Retis, 2006a; 2013c). El análisis de las macro-, meso- y microcondiciones de la producción y circulación de la información en la prensa de referencia demuestra las diversas variables implicadas en esta tendencia y cómo el discurso mediático reproduce las estrategias de estratificación social que se producen en entornos geográficos, políticos y económicos (Retis, 2006a); esto es aún más evidente en el caso de los jóvenes (García y Retis, 2011) y las mujeres (Galán y Retis, 2013; Retis, 2013c). El discurso de la prensa de referencia constituye, por ende, el espejo de la realidad donde los inmigrantes latinoamericanos no alcanzan a verse reflejados. En los grupos de discusión hemos comprobado cómo reconocen que se trata de espacios donde se les representa de una manera distorsionada. Por tanto, recurren a otros espacios mediáticos donde encuentran no solo información de interés específico sobre el proceso de llegada y asentamiento, las leyes migratorias, oportunidades laborales, sino también de espacios de autorrepresentación. Estos son espacios mediáticos diaspóricos en los que confluyen flujos de información y comunicación transnacional de los lugares de origen, de los lugares de asentamiento y de la naturaleza de la vida migrante. Estos espacios han sido ubicados principalmente en los entornos urbanos de las ciudades globales, aquellas a donde los migrantes latinoamericanos han llegado buscando oportunidades laborales, principalmente en sectores de servicios, construcción e industrias varias (Retis, 2006a, 2006b, 2014a, 2014b). 


\section{Diásporas y medios en contextos urbanos}

El hecho de que, en el 2015, el Reporte Mundial sobre las Migraciones en el Mundo estuviera dedicado íntegramente a las ciudades fue un claro reconocimiento a la centralidad de las metrópolis como destino de las migraciones internacionales y como principal contexto de integración de los migrantes (OIM, 2015). El reporte del 2018 vuelve a insistir en que el crecimiento de la influencia de las ciudades sobre los asuntos sociales y económicos y sobre las trayectorias migrantes, tanto internacionales como internas, demanda una mayor atención por parte de los investigadores y los políticos. En el 2016, y por primera vez, la Cumbre Mundial de Líderes Locales y Regionales incluyó el tema de la inmigración en la agenda; esta culminó con la Declaración de Bogotá, en la cual los signatarios llamaron a la acción local hacia la urbanización sostenible. El Parlamento Mundial de Alcaldes del Programa de las Naciones Unidas para los Asuntos Urbanos adoptó la migración como una de sus prioridades en la Conferencia Habitat III, que se realizó en Quito (OIM, 2018).

Desde el 2008, y por primera vez en nuestra historia, la mitad de la población en el mundo empezó a residir en ciudades. Según el reporte de la OIM del 2015, en el 2014 la proporción subió a $54 \%$ y se prevé que para el 2050 la población urbana alcance unos 6400 millones de personas. Es más, se estima que cada semana hay 3 millones de personas en el mundo que se instalan en ciudades y que uno de cada cinco migrantes nacidos en el extranjero vive en una de las 20 ciudades más pobladas del mundo. Esto ha hecho que para muchas ciudades la migración se haya convertido en un factor de crecimiento poblacional (OIM, 2015). La geografía de los flujos migratorios está cambiando en consonancia con la economía mundial y hay ciudades como Los Ángeles, Londres, Nueva York o Miami, por ejemplo, donde los migrantes representan más de una tercera parte de los residentes. En ciudades como Madrid, se estima que es el $20 \%$ y en metrópolis asiáticas como Tokio, aunque el porcentaje es menor ( $3 \%)$, igualmente se vienen propiciando reacomodos en los circuitos metropolitanos.

La aceleración de la movilidad humana, marcadamente urbana, viene demandando nuevos enfoques de gobierno y políticas migratorias que pongan freno a las asimetrías entre las políticas nacionales y locales. Como destaca el informe de la OIM (2015), a pesar delainnovación en ciertas ciudades, las autoridades de los gobiernos metropolitanos todavía no conceden la debida prioridad a las iniciativas, con miras a la reducción de la pobreza, que prevén la inclusión de los migrantes. En este contexto, destaca, los migrantes deberían de ser valorados no únicamente en términos de las remesas que envían a sus lugares de origen, sino en tres aspectos fundamentales: 1) como forjadores de resiliencia de las comunidades de origen y destino, a través del intercambio de recursos y la prestación de apoyo; 
2) como agentes de desarrollo local, ya que forjan vínculos entre las ciudades de origen y destino, y 3) como forjadores de las ciudades, pues pueden contribuir a fortalecer el lugar que ocupan las metrópolis en la jerarquía económica y política mundial.

Los migrantes latinoamericanos se han establecido en diversas ciudades que constituyen centros de atracción para el flujo de capital y poblaciones, y que actúan como nodos dentro del sistema económico mundial. En las revisiones históricas (Retis, 2013a; 2013b) y el trabajo de campo se ha analizado cómo, a la vista de los procesos de estratificación social urbana y la tendencia de la prensa de referencia a cubrir los temas sobre inmigración desde una perspectiva discriminatoria, surgen medios de comunicación alrededor de los "enclaves étnicos" (Wilson y Portes, 1980; Portes y Schafer, 2006). Los medios de comunicación dirigidos a inmigrantes construyen espacios de información, comunicación y autorrepresentación, pero también fungen como espacios de comercialización de consumidores de productos y servicios específicos (Retis, 2006b). Estos han sido identificados como "espacios mediáticos" porque constituyen proyectos hiperlocales, locales y translocales que coexisten con otros medios de comunicación no solamente en sus formas de producción, sino también en sus circuitos de circulación y consumo. Debido al hecho de que sirven a la comunidad migrante, la mayoría de ellos tienden a ser identificados como medios comunitarios, a pesar de que en gran parte provienen de empresas privadas. Estos son proyectos realizados en el marco de las empresas dirigidas por y para los inmigrantes; en algunos casos, paradójicamente, estos no provienen de empresarios inmigrantes, sino de negociantes locales que se incorporan en el mercado de productos y servicios específicos para inmigrantes (Retis, 2006b).

El trabajo de campo que se desarrolló en Madrid, Londres, Miami, Nueva York, Los Ángeles, y más recientemente en Tokio, ha permitido analizar cómo los inmigrantes recién llegados buscan informarse sobre la legislación vigente en asuntos migratorios, mercado de trabajo, sanidad y actividades festivas locales, entre otros temas de interés específicos. Pero también continúan interesados en informarse sobre los acontecimientos que afectan a sus familiares en los países de origen. Sus intereses conforman espacios translocales, similares y a la vez distintos a los otros residentes de la ciudad en la que viven, semejantes y a la vez diferentes a sus familiares en sus ciudades de origen. Las entrevistas, los grupos de discusión y las prácticas de observación participante han permitido comprobar estas sinergias, más evidentes en los primeros estadios del proceso migratorio (Retis, 2006b; 2011; 2018a).

El análisis comparado ha permitido identificar también cómo, frente al discurso de la exclusión, aparece un discurso inclusivo proveniente principalmente de la publicidad y el marketing étnico, que busca captar a los nuevos consumidores, tengan o no permisos de 
trabajo y residencia. En diversos estudios se constató, por un lado, la necesidad de plataformas de distribución de anuncios publicitarios por parte de empresas de diversa índole, desde compañías transnacionales, pasando por medianas empresas hasta pequeños negocios dirigidos a los nuevos consumidores. Estas sinergias del mercado publicitario confluyen con las necesidades de los inmigrantes en términos de representación normalizada y autorrepresentación, así como de cauces de información específica. Por otro lado, en ciudades donde el idioma oficial no es el español o el portugués, son los medios dirigidos a grupos latinoamericanos los que vienen funcionando como traductores lingüísticos y muchas veces como traductores culturales. En las entrevistas con los productores de estos medios, se ha constatado su interés por brindar a sus audiencias información que identifican como fundamental para la vida cotidiana en la ciudad donde residen. Como consecuencia, sean públicos o privados, los medios dirigidos a las comunidades diaspóricas terminan realizando la función social del servicio público. Esta paradoja hace que sea muy complejo asignarles una etiqueta homogénea. Se trata, más bien, de disímiles proyectos de comunicación e información.

En metrópolis con un largo historial de medios latinos, como pueden ser Los Ángeles, Nueva York o Miami, estos medios se han consolidado como referentes para las comunidades hispanohablantes, con agendas de información específicas y con un compromiso social con sus audiencias, de tal manera que, no en pocas ocasiones, han sido criticados por otros medios de falta de objetividad. En realidad, se trata de medios que ejercitan prácticas del civic advocacy journalism, un tipo de periodismo fundamental y necesario en el panorama mediático latino estadounidense (Retis, 2018a). En el otro lado del Atlántico, se han identificado medios latinos más jóvenes, pero igualmente comprometidos con las audiencias a las que sirven. En Londres, por ejemplo, los diversos medios identificados circulan alrededor de los principales enclaves étnicos de la ciudad y tienen una presencia significativa en los establecimientos de consumo y servicios varios. En Madrid, los medios latinos fungieron como principales vías de información, comunicación y autorrepresentación durante los años de la acrecencia de los flujos. Pero incluso ahora que muchos han desaparecido, se mantienen algunos que todavía proveen información específica para las audiencias latinoamericanas en la capital española. Al otro lado del Pacífico, los medios latinos en Tokio sirven a sus audiencias principalmente en portugués y en español. En este contexto, hemos identificado además una fuerte dependencia a las redes sociales de este tipo de medios, debido a que la fluidez para entender el japonés escrito $y$ hablado supone un reto para una parte importante de inmigrantes latinos en Japón. En todos estos entornos urbanos, se ha identificado además un consumo cotidiano de medios producidos en los países de origen. Ya sea por servicios de 
televisión de pago, por cable, por satélite $\mathrm{o}$, más recientemente, por consumo en internet o en aplicaciones en los teléfonos inteligentes, los latinoamericanos que residen en el exterior leen, escuchan y ven medios producidos en sus países de origen, $\mathrm{o}$, más concretamente, medios producidos en su ciudad de origen.

\section{Apuntes para la reflexión}

El análisis comparado de los medios dirigidos a inmigrantes latinoamericanos en ciudades globales del Norte económico nos ha permitido analizar por qué, cuando estudiamos recientes procesos de llegada y establecimiento de grupos migrantes en ciertas áreas geográficas, identificamos un incremento coyuntural de medios preexistentes o la creación y el desarrollo de nuevos proyectos de medios. El análisis comparado de estas sinergias respecto de ciudades con una larga trayectoria como receptoras de inmigración latinoamericana (como Los Ángeles o Nueva York) frente a ciudades con un periodo temporal medio (como Madrid) o de reciente recepción de inmigrantes latinoamericanos (como Londres) permite identificar tendencias semejantes, pero también especificidades y diferencias en las prácticas comunicativas. En Londres, por ejemplo, inmigrantes colombianos, ecuatorianos o bolivianos confluyen con otros inmigrantes latinoamericanos provenientes de España que protagonizan su segundo o tercer proyecto migratorio.

El carácter cambiante de las migraciones contemporáneas se constata también en los espacios mediáticos. Hemos realizado varios mapeos de medios étnicos en Norteamérica y Europa y hemos constatado cómo resulta prácticamente imposible que la contabilidad de los medios dirigidos a inmigrantes latinoamericanos en ciudades globales permanezca inamovible. Durante los años de conteo y seguimiento de las iniciativas de fundación y desarrollo de medios dirigidos a inmigrantes latinoamericanos en Madrid o Londres, por ejemplo, se ha comprobado la volatilidad de los proyectos. Hemos encontrado tendencias similares en Miami, Nueva York o Los Ángeles. En todos estos estudios comparados ha estado presente la multidimensionalidad de sus estructuras. Los recuentos dan cuenta de grandes empresas transnacionales que se comportan como medios de referencia, pero también de sociedades de mediano alcance frente a pequeñas empresas y hasta proyectos unipersonales.

Los orígenes de los medios dirigidos a latinoamericanos en ciudades globales también son variables. Los recuentos por ciudades han arrojado, en todos los casos, propuestas comerciales, iniciativas públicas o proyectos comunitarios. Estos medios conviven y compiten en mayor o menor medida con otros espacios públicos o privados de las migraciones internacionales. En los reportes elaborados, se han encontrado espacios mediáticos locales, regionales, nacionales, pero también se han identificado proyectos hiperlocales o, más bien hiperglocales: aquellos que surgen 
a partir de las necesidades de comunicación e información que conectan comunidades locales tanto en países de origen como de destino, en un espectro global (Retis 2006b, 2014a, 2018b).

La globalización del capitalismo implica también la globalización de sus desigualdades intrínsecas y el estudio de las migraciones recientes permite identificar cómo se generan procesos de desigualdad social económica y espacial (Canales, 2006; Sassen, 2003). Si la desigualdad social se concibe como un acceso desigual a los recursos, los servicios y las posiciones que la sociedad valora, la estratificación social apunta a que esta desigualdad va tomando cuerpo o se va institucionalizando, promoviendo un sistema de relaciones sociales que determina quién recibe qué y por qué (Kerbo, 2004). La globalización económica que favoreció la movilidad de los flujos de capital no ha permitido la misma flexibilidad en términos de movilidad social a los migrantes internacionales (Retis, 2006a, 2006b); en este contexto, la emergencia de nuevas formas globales, posnacionales y transnacionales de ciudadanía suponen un reto cuando los derechos culturales transnacionales no se pueden ejercer de manera plena, particularmente si es en términos de acceso a medios de información y comunicación (Moreno y Retis, 2014).

En los últimos cuarenta años, los latinoamericanos se han ido incorporando al contexto de la migración internacional como resultado de condiciones geopolíticas y realineamiento de relaciones laborales más allá de las fronteras. Las migraciones latinoamericanas no suponen una ruptura con las raíces territoriales, sino la configuración de un campo social transnacional a través del cual la comunidad de origen se transforma en los lugares de destino. A lo largo de estas décadas, se han venido consolidando comunidades diaspóricas latinoamericanas, construidas en un espacio imaginario más que físico, en que los medios de comunicación constituyen un elemento central.

Las nuevas plataformas tecnológicas, las redes sociales y la inmediatez de la comunicación virtual dan cuenta de procesos de comunicación transnacionales en los que las identidades individuales y colectivas reproducen complejas dinámicas históricas, sociales y culturales. En este sentido, necesitamos entender los impactos que las dinámicas sociales de las agrupaciones transnacionales tienen en sus propios miembros y en otros, pues están emergiendo como elementos clave en los procesos de globalización. Aunque las diásporas son vistas como formas alternativas de las estructuras del capitalismo mundial, en muchos casos ellas mismas son participantes de las actividades económicas internacionales (Karim, 2003); de ahí la importancia de observar las dinámicas de los grupos latinoamericanos en sus contextos transnacionales.

El análisis comparado de las recientes migraciones a ciudades europeas $y$ norteamericanas permite indagar tendencias sobre la conformación del 
transnacionalismo diaspórico y el rol de los espacios mediáticos. Desde una perspectiva multidisciplinar se ha ido constatando cómo los inmigrantes acceden de manera compleja, diferenciada, y a veces contradictoria, a los usos y consumos de medios de información y comunicación. Las entrevistas en profundidad, así como los grupos de discusión y prácticas de observación participante, permiten aportar hallazgos cualitativos que, aunque no se pueden extrapolar en su carácter cuantitativo, sí sirven para identificar estrategias significativas en el contexto de los espacios mediáticos transnacionales contemporáneos. El estudio comparado de las múltiples dimensiones en los procesos de producción, distribución y consumo permitirá aportar más elementos para comprender las prácticas mediáticas en el transnacionalismo diaspórico de los latinoamericanos. Estas sinergias, en palabras de García Canclini (2009), son producto de dinámicas internas en relación con las nuevas modalidades de subordinación de las economías periféricas, la reestructuración transnacional de los mercados de bienes materiales y comunicacionales. Confiamos en que el estudio de la génesis, el desarrollo y la evolución de espacios mediáticos migrantes que sirven a los latinoamericanos en el norte económico pueda aportar algunas pistas para el examen de los ahora crecientes movimientos migratorios entre ciudades al interior de la región latinoamericana.

\section{Referencias}

Appadurai, A. (1996). Modernity at large. Cultural dimensions of globalization. Minneapolis: University of Minessota Press.

Asakura, T., y Murata, A. (2006). Demography, immigration background, difficulties with living in Japan, and psychological distress among Japanese Brazilians in Japan. Journal of Immigrant and Minority Health, 8(4), 325-338.

Canales, A. (2006). Los inmigrantes latinoamericanos en Estados Unidos: inserción laboral con exclusión social. En A. Canales (Ed.), Panorama actual de las migraciones en América Latina (pp. 81-116). Universidad de Guadalajara.

Canales, A. (2011). Las profundas contribuciones de la migración latinoamericana a los Estados Unidos. En J. Martínez (Ed.), Migración internacional en América Latina y el Caribe. Nuevas tendencias, nuevos enfoques (pp. 257-331). Santiago de Chile: CEPAL.

Casilda, R. (2002). La década dorada. Economía e inversiones españolas en América Latina 1990-2000. Madrid: Ediciones Universidad de Alcalá.

Castells, M. (2006). La sociedad red: una visión global. Madrid: Alianza Editorial. 
Castells, S., y Miller, T. (2004). La era de la migración. Movimientos internacionales de población en el mundo moderno. Universidad Autónoma de Zacatecas.

Colectivo Ioé. (2008). Inmigrantes, nuevos ciudadanos. ¿Hacia una España plural $e$ intercultural? Recuperado de https:/www.colectivoioe.org/uploads/ b225ac1dc83b7bebdda55da3c4e7ef65a1cd9a72.pdf

Cottle, S. (2000). Media research and ethnic minorities: mapping the field. En S. Cottle (Ed.), Ethnic minorities and the media (pp. 1-30). Buckingham: Open University Press.

Dávila, A. (2001). Latinos Inc. The marketing and making of a people. Berkeley: University of California Press.

Dwyer, T. (2010). Media convergence. Berkshire: Open University Press.

Ennis, S. R., Ríos-Vargas, M., y Albert, N. G. (2011). The Hispanic Population: 2010. 2010 Census Briefs. United States Census Bureau. Recuperado de https://www. census.gov/prod/cen2010/briefs/c2010br-04.pdf

Galán, E., y Retis, J. (2013). Discursos en torno a la inmigración en España: análisis comparado de la cobertura periodística y los programas de ficción. En M. García, (coord.), Al descubierto. El poder democrático de los medios (pp. 93-125). Madrid: Fragua.

García Canclini, N. (2002). Latinoamericanos buscando lugar en este siglo. Ciudad de México: Siglo XXI.

García, P., y Retis, J. (2011). Jenues et minorités ethniques dans la presse européenne: Les medias et les émeutes parisiennes de 2005. Global Media Journal, 4(1), 77-92.

García, A., Retis, J., y Román P. (octubre del 2016). Reflexiones en torno a la investigación sobre ciudad y comunicación: mediaciones sociales e intersecciones espaciales. Ponencia presentada al XIII Congreso Latinoamericano de Reflexiones Críticas desde América Latina, Ciudad de México.

Georgiou, M. (2006). Diaspora, identity and the media: diasporic transnationalism and mediated spatialities. Londres: Hampton Press.

Georgiou, M., y Silvertone, R. (2007). Diasporas and contra-flows beyond nationcentrism. En D. Thussu (Ed.), Media on the move: global flow and contra-flow (pp. 33-49). Londres: Routledge.

González, J. (2011). Harvest of Empire. A history of Latinos in America. Nueva York: Penguin.

Grupo Intesdisciplinario de Investigador@s Migrantes. (Coord.). (2010). Familias, niñas, niños y jóvenes migrantes. Rompiendo estereotipos. Madrid: IEPALA. Recuperado de https:/giim.files.wordpress.com/2010/07/giim-rompiendoestereotipos.pdf 
Guarnizo, L., y Smith, M. (1998). Transnationalism from below. New Brunswick: Transaction Publishers.

Guillespie, M. (2003). Transnational communities and diaspora communities. En S. Cottle (Ed.), Ethnic minorities and the Media (pp. 164-177). Philadelphia: Open University Press.

Higuchi, N. (2006). Brazilian migration to Japan. Trends, modalidities and impact. United Nations Expert Group Meeting on International Migration and Development in Latin America and the Caribbean. Ciudad de México: United Nations.

Hondagneu-Sotelo, P. (2001). Doméstica: immigrant workers cleaning and caring in the shadows of affluence. Los Angeles: University of California Press.

Husband, C. (2000). Media and the public sphere in multi-ethnic societies. En S. Cottle (Ed.), Ethnic minorities and the media. Philadelphia: Open University Press.

Izquierdo, A., López, D., y Martínez, R. (2002). Los preferidos del siglo xxi. La inmigración latinoamericana en España. En F. García Castaño y C. Muriel (Eds.), La inmigración en España. Contextos y alternativas (pp. 237-249). Granada: Laboratorio de Estudios Interculturales.

Karim, K. (2003). Mapping diasporic media scapes. En K. Karim (Ed.), The media of diaspora (pp. 1-17). Nueva York: Routledge.

Kerbo, H. (2004). Estratificación social y desigualdad. El conflicto de clase en perspectiva histórica, comparada y global. Madrid: McGraw Hill.

Levitt, P., y Glick Schiller, N. (2004). Conceptualizing simultaneity: a transnacional social field perspective on society. International Migration Review, 38(145), 595-629.

Martínez, J. (2006). Inmigración internacional, derechos humanos y desarrollo. Santiago de Chile: CEPAL.

Martínez, J. (2008). América Latina y el Caribe: migración internacional, derechos humanos y desarrollo. Santiago de Chile: CEPAL.

Martínez, J. (2011). Migración internacional en América Latina y el Caribe. Nuevas tendencias, nuevos enfoques. Santiago de Chile: CEPAL.

Martínez, J., Cano, V., y Contrucci, M. (2014). Tendencias y patrones de la migración latinoamericana y caribeña hacia 2010 y desafíos para una agenda regional. Santiago de Chile: CEPAL.

Massey, D., Arango J., Hugo, G., Kouaouci A., Pellegrino, A., y Taylor, J. (1994). International migration theory: The North American case. Population and Development Review, 20(4), 699-751.

Matsaganis, M., Katz, V., y Ball-Rokeach, S. (2010). Understanding ethnic media. Producers, consumers and societies. Thousand Oaks: Sage.

Mignolo, W. (2005). The idea of Latin America. Malden: Blackwell Publishing. 
Moreno, J., y Retis, J. (enero del 2014). La apropiación del espacio público en contextos rurales. Experiencias de mediación tecnológica en el desarrollo comunitario. Ponencia presentada em el IV Congreso Internacional de la Asociación Española de Investigación de la Comunicación, Universidad del País Vasco, Bilbao, España.

Naciones Unidas. (2004). Estudio económico y social mundial. Migración internacional. Nueva York: Publicaciones de las Naciones Unidas.

Organización Internacional para las Migraciones. (2011). Informe sobre las migraciones en el mundo 2011. Ginebra: Autor. Recuperado de http://publications.iom.int/ books/informe-sobre-las-migraciones-en-el-mundo-2011

Organización Internacional para las Migraciones. (2015). Informe sobre las migraciones en el mundo 2015. Los migrantes y las ciudades: nuevas colaboraciones para gestionar la movilidad. Ginebra: Autor. Recuperado de http://publications.iom. int/system/files/wmr2015_sp.pdf

Organización Internacional para las Migraciones. (2018). Informe sobre las migraciones en el mundo 2018. Ginebra: Autor. Recuperado de https://publications.iom.int/ system/files/pdf/wmr_2018_sp.pdf

Passel, J., Cohn, D., y Lopez, M. (2011). Census 2010: 50 million Latinos. Hispanics account for more than half of nation's growth in past decade. Washington: Pew Hispanic Center.

Pedone, C. (2006). Estrategias migratorias y poder: tú siempre jalas a los tuyos. Quito: Abya Yala.

Pellegrino, A. (2003). La migración internacional en América Latina y el Caribe: tendencias y perfiles de los migrantes. Santiago de Chile: CEPAL.

Pellegrino, A. (2004). Migration from Latin America to Europe: trends and policy challenges. Geneva: International Organization for Migration.

Portes, A., y Shafer, W. (2006). Revisiting the enclave hypothesis: Miami twenty-five years later [CMD Working Paper 06-10]. The Center for Migration and Development, Princeton University.

Quijano, A. (2007). Coloniality and modernity rationality. Cultural Studies, 21(2/3), 168-178.

Retis, J. (2006a). El discurso público sobre la inmigración extracomunitaria en España. Análisis de la construcción de las imágenes de los inmigrantes latinoamericanos en la prensa de referencia (tesis doctoral para el Programa de Doctorado en América Latina Contemporánea). Instituto Universitario de Investigación Ortega y Gasset, Universidad Complutense de Madrid.

Retis, J. (2006b). Espacios mediáticos de la inmigración en Madrid: génesis y evolución. Madrid: OMCI. 
Retis, J. (2011). Estudio exploratorio sobre el consumo cultural de los inmigrantes latinoamericanos en España. El contexto transnacional de las prácticas culturales. Madrid: Fundación Alternativas.

Retis, J. (2013a). Spanish language television in the United States. En C. Tatum (Ed.), Encyclopedia of Latino culture: from calaveras to quinceañeras (pp. 835-847). California: Greenwood.

Retis, J. (2013b). Spanish language newspapers in the United States. En C. Tatum (Ed.). Encyclopedia of Latino culture: from calaveras to quinceañeras (pp. 815-823). California: Greenwood.

Retis, J. (2013c). Immigrant Latina images in mainstream media: class, race and gender in public discourses of the United States and Spain. En M. Lirola (Ed.), Discourses on Immigration in Times of Economic Crisis. A critical perspective (pp. 28-58). Londres: Cambridge Scholars Publishing.

Retis, J. (2014a). Latino diasporas and the media. Interdisciplinary approaches to understand transnationalism and communications in global cities. En F. Darling-Wolf (Ed.), The International Encyclopedia of Media Studies: Research Methods in Media Studies (v. 7). Nueva Jersey: Wiley-Blackwell.

Retis, J. (2014b). El rol de los medios en los procesos de estratificación social en el contexto migratorio: espacios mediáticos y consumos culturales. Revista Latinoamericana de Comunicación Chasqui, (125), 13-22.

Retis, J. (2018a). Hashtag jóvenes latinos: challenges and opportunities of teaching civic advocacy journalism in "glocal" contexts. En M. Castañeda y J. Krupczynski (Eds.), Learning from diverse Latina/o communities: social justice approaches to civic engagement (229-250). Nueva York: Palgrave.

Retis, J. (2018b). Homogenizing heterogeneity in transnational contexts. Mapping Latin American diasporas and the media in the global North. Manuscrito en edición.

Retis, J., y Badillo, A. (2015). Los latinos y las industrias culturales en español en Estados Unidos. Madrid: Real Instituto Elcano.

Retis, J., y Badillo, A. (2018). Los circuitos de la cultura en español en Estados Unidos: Nueva York, Los Angeles, Miami. Madrid: Real Instituto Elcano.

Retis, J., y Moreno, J. (enero del 2014). La apropiación del espacio público en contextos rurales. Experiencias de mediación tecnológica en el desarrollo comunitario. Ponencia presentada en el IV Congreso de la Asociación Española de Investigación de la Comunicación (AE-IC), Bilbao.

Rodríguez, J. (2017). Efectos de la migración interna sobre el sistema de asentamientos humanos de América Latina y el Caribe. Revista CEPAL, (123), 8-33.

Said, E. (1993). Culture and imperialism. Londres: Vintage. 
Sassen, S. (2001). The global city. New York, London, Tokyo (2. ${ }^{\text {a }}$ ed.). Princeton: Princeton University Press.

Sassen, S. (2003). Los espectros de la globalización. Buenos Aires: Fondo de Cultura Económica.

Sinclair, J., y Cunningham, S. (2000). Diasporas and the media. En S. Cunningham y J. Sinclair (Eds.), Floating lives: the media and Asian diasporas (pp. 1-34). Queensland: University of Queensland Press.

Sinclair, J., y Straubhaar, J. (2013). Latin American television industries. Londres: British Film Institute, Palgrave Macmillan.

Smith, P., y Guarnizo, L. (Eds.). (1998). Transnationalism from below. New Brunswick: Transaction Publishers.

Solimano, A., y Watts, N. (2005). International migration, capital flows and the global economy: a long run view. Santiago de Chile: CEPAL.

Sreberny, A. (2003). Media and diasporic consciousness: an exploration among Iranians in London. En S. Cottle (Ed.), Ethnic minorities and the media (pp. 179-196). Buckingham: Open University Press.

Stepler, R., y Lopez, H. (2016). U. S. Latino population growth and dispersion has slowed since onset of the great recession. Pew Research Center. Recuperado de www. pewhispanic.org/wp-content/uploads/sites/5/2016/09/PH_2016.09.08_ Geography.pdf

Thussu, D. (2007). Media on the move: global flow and contra-flow. Londres: Routledge.

Tsuda, T. (2004). Media images, immigrant reality: ethnic prejudice and tradition in Japanese media representations of Japanese-Brazilian return migrants [working paper 107]. The Center for Comparative Immigration Studies.

United Nations. (2016). The world's cities in 2016. Washington: Autor.

Wilson, K., y Portes, A. (1980). Immigrants enclaves: an analysis of the labor market experiences of Cubans in Miami. American Journal Sociology, (86), 295-319.

Wilson, C., Gutiérrez, F., y Chao, L. (2003). Racism, sexism, and the media. Sage Publications.

Yúdice, G. (2009). Culturas emergentes en el mundo "hispano" de Estados Unidos. Madrid: Fundación Alternativas. 